\title{
Seasonal and Annual Trend of Cyclonic Disturbances over the Bay of Bengal
}

\author{
M. A. K. Mallik ${ }^{1,2^{*}}$, M. A. M. Chowdhury ${ }^{2}$, M. N. Ahasan $^{3}$, Md. A. E. Akhter ${ }^{4}$ \\ and S. M. Quamrul Hasan ${ }^{1}$ \\ ${ }^{I}$ Bangladesh Meteorological Department, Agargaon, Dhaka, Bangladesh \\ ${ }^{2}$ Department of Physics, Jahangirnagar University, Savar, Dhaka, Bangladesh \\ ${ }^{3}$ Feni University, Feni, Bangladesh \\ ${ }^{4}$ Department of Physics, Khulna University of Engineering and Technology, Bangladesh
}

\begin{abstract}
An attempt has been made to find out the monotonic seasonal and annual trend of categorical cyclonic disturbances formed over the Bay of Bengal (BoB) during 1981-2013. Long term trend of categorical cyclonic disturbances frequency over the Bay of Bengal is analyzed by using Mann-Kendal test and Sen's slope estimation. The analysis shows that the frequency of Depression over BoB during monsoon season shows a decreasing trend in $90 \%$ significant confidence level. The pre-monsoon season and the annual trend of depression frequency also show a decreasing trend but they are not statistically significant. The post-monsoon season and the annual trend of cyclonic storm shows a decreasing trend but not statistically significant. From the trend analysis of frequency of severe cyclonic storm, it is found that the post-monsoon season and the annual frequency are decreasing in 95\% significant confidence level. But no trend is found in the pre-monsoon season. The trend of total frequency of cyclonic disturbances (depression, cyclonic storm and severe cyclonic storm) shows a decreasing trend during monsoon season in 95\% statistical confidence level and in other seasons as well as the annual show insignificant trend.
\end{abstract}

Keyword: Categorical cyclonic disturbance, Trend, Mann-Kendal and

\section{Introduction}

A series of cyclonic low-pressure systems form over the Bay of Bengal $(\mathrm{BoB})$ during the pre-monsoon, monsoon and post-monsoon season and move in a west, north-west, north or northeast direction across the northeastern India, Bangladesh and Myanmar land mass. Generally, these low-pressure systems form over the different regions of the Bay of Bengal and the regions are shown in fig- 1 . These cyclonic systems are categorized in Bangladesh and India as low (L), well marked low (WL), Depression (D), Deep Depression (DD), Cyclonic Storm (CS), Severe Cyclonic Storm (SCS) and Very Severe Cyclonic Storm (VSCS) and is depicted in Table-1. A low pressure system with only one closed isobar and the surface winds in cyclonic circulation less than $31 \mathrm{Kmh}^{-1}$ is referred to as low. A low pressure system with 2 or 3 closed isobars at $2 \mathrm{hPa}$ interval and the surface wind in cyclonic circulation between $41-51 \mathrm{Kmh}^{-1}$ is referred to as depression. Depression in which the wind speed exceeds $61 \mathrm{Km}^{-1}$ is termed as cyclonic storm. There are two Tropical Cyclone (TC) seasons in the BoB, one concentrated in March-May (pre-monsoon) and the other spanning October-November (post-monsoon). In between the pre-monsoon and post-monsoon seasons, monsoon depressions become active in the $\mathrm{BOB}$, but seldom grow to $\mathrm{TC}$ force owing to increased vertical easterly shear during the mature monsoon phase. Pre-monsoon TCs mainly develop from low-pressure systems in the equatorial Indian Ocean that then migrate northward into the BoB.

The frequency of Tropical cyclone (TC) over the North Indian Ocean is a significant weather parameter for the coastal population of South Asian nations. Majority of intense cyclones forms during post monsoon (especially during October and November) and pre-monsoon (especially during May). During the pre-monsoon period cyclones of Bay of Bengal generally move northward and strike Northeast coast of India or Bangladesh coast after re-curvature. A pronounced shift towards the West-central Bay occurs during the post-monsoon period due to which most of the cyclones strike Southeast coast of India and some of them even cross Sri Lanka coast. The months of November and May account for highest number of intense cyclones. The cyclone frequency exhibits variations of different time scales. For instance interannual variations in the frequency have been documented by Shapiro (1982), Gray (1984), Nicholls (1984) and Chan (1985). ENSO seems to influence the tropical cyclone frequency. Lesser number of post-monsoon cyclones tends to form over the North Indian Ocean during ENSO years (Singh and Rout, 1999). Other than inter-annual variations there are variations of other time scales also. If long -term variations of cyclone frequency are properly documented then the epochs of higher and lower frequencies could be foreshadowed much in advance. It is well known that the Indian summer monsoon is maintained by northward progression of the inter tropical convergence zone (ITCZ Sikka and 
Gadgil 1980) and the synoptic scale disturbances, commonly known as monsoon depressions (MDs), which generally form over the Bay of Bengal $(\mathrm{BoB})$ or cross over to the $\mathrm{BoB}$ from south-China sea and propagate westward/northwestward to the mainland (Ding and Sikka 2006). It is not uncommon that MDs move northwestward along the monsoon trough and reach as far as northwestern India/Pakistan and produce large rainfall totals (sometimes up to 300-400mm) along its track (Sikka 1977). As far as agriculture is concerned, MDs are very important, especially in central India as it could act as a main source of moisture (Sivakumar et al 2005). Some studies have reported a decreasing trend in the observed frequency of MDs in the recent decades (Patwardhan and Bhalme 2001, Kumar and Dash 2001, Mandke and Bhide 2003), while some other studies noted that along with the decreasing trend in MDs there is an increasing trend in the number of low pressure systems (Rajeevan et al 2000, Kumar and Dash 2001, Jadhav and Munot 2009). Nevertheless, understanding the reasons behind the decreasing trend in MDs is one of the most important science questions to be addressed. High sea surface temperature (SST), presence of low level $(850 \mathrm{hPa}$ ) cyclonic vorticity over the BoB, high midtropospheric humidity and weak vertical wind shear are considered to be the essential environmental conditions for the formation and intensification of MD (Sikka 1977). Interestingly, these are the same essential criteria for the genesis of tropical cyclones as suggested by Gray (1968). However, it may be noted that the vertical wind shear is very strong particularly over the Arabian Sea and the BoB during the monsoon season. This is a major factor that limits the synoptic scale disturbances from intensifying into tropical cyclones during this season, while in all other basins in the Northern Hemisphere, cyclone activity peaks in July-August (Gray 1968, 1979, Sikka 1977; and references therein).

Recent studies of Rao et al (2004) and Rao et al (2008) suggested that the variation in the strength of upper tropospheric wind could modulate the frequency and intensity of the storms over northern Indian Ocean. It may be worth to note that the decadal variability of low-level vorticity and vertical and horizontal wind shear of zonal wind are in the unfavorable phase for the genesis and intensification of CS over the BoB after 1980 (Mandke and Bhide 2003). Rajeevan et al (2000) reported that SST in the BoB and frequency of MD had shown similar decadal variations till early 1980s, however the MD have been decreasing in-spite of increasing SST since mid-1980s. Prajeesh et al (2013) suggested that the decreasing trend in the frequency of occurrence of MD could be associated with the declining trend in mid-tropospheric relative humidity. Roxy et al (2015) observed that the decreasing trend in the rainfall activity over the central-eastern India is intriguing as this is the region which receives substantial amount of rainfall due to MDs/low pressure systems. This motivated us to explore whether there is any link between the decreasing trend in MDs and rainfall over the central-eastern Indian region and if so, whether the latter is also influenced by the changes in the monsoonal circulation as suggested by Roxy et al (2015). In fact, some of the studies on the long term variation of MD indicate that the changes in the 'large scale environmental parameters' are responsible for the decreasing trend in the frequency of MD over the BoB, which could be related to the changes in the circulation that Roxy et al (2015) refer to. Hence, in this paper, we try to address the links between the trends in the monsoon rainfall in India and the frequency of MDand derive the quantitative estimates of the relative contributions of each of the environmental variables responsible for the long term variation in the number of MD. The Genesis potential index (GPI) formulated by Emanuel and Nolan (2004) is a useful tool to quantitatively describe the influence of large-scale environmental factors on the genesis of the tropical cyclones.GPI has been successfully used to analyze the seasonal, intra-seasonal and interannual modulation of tropical storm activity in various tropical basins (Camargo et al 2007, Camargo et al 2009, Yanase et al 2012, Li et al 2013, Girishkumar et al 2014). Given the fact that the environmental conditions responsible for the organization of the low pressure systems to depressions and cyclones are same (Sikka 1977), it is possible to use the GPI for estimating the relative contributions of different environmental conditions in the formation and development of MD.The objective of the present study is to analyze the trend of cyclonic disturbances categorically formed over the BoB on seasonal and annual basis for the period of 1981-2013 using Mann-Kendal test and Sen's slope estimation.

\section{Data Used And Methodology}

Daily rainfall data set over Bangladesh of 28 meteorological observatories (Fig-1) during the period from 1985 to 2014 has been used in the present study which was collected from the Climate Division of Bangladesh Meteorological Department (BMD). As per the classifications of BMD the rainfall events are divided into five different categories from 'light' to 'very heavy' depending on the amount of rainfall in a day for the station rainfall (Table I). The same classification is used in the present study for identifying categorical rainfall events. In the present analysis the spatial and temporal variability along with the longterm trend of five broad categories of rainfall events are analyzed and discussed. The Mann-Kendall (MK) test is used for the detection of monotonic trends in the derived frequency and intensity data for each grid cell. An estimate of the Sen's slope, a strong estimate of the monotonic trend, is also computed, along with its significance level. The MK test is a rank-based test, with no assumptions as to the underlying probability distribution of data [Helsel and Hirsch, 1992]. 


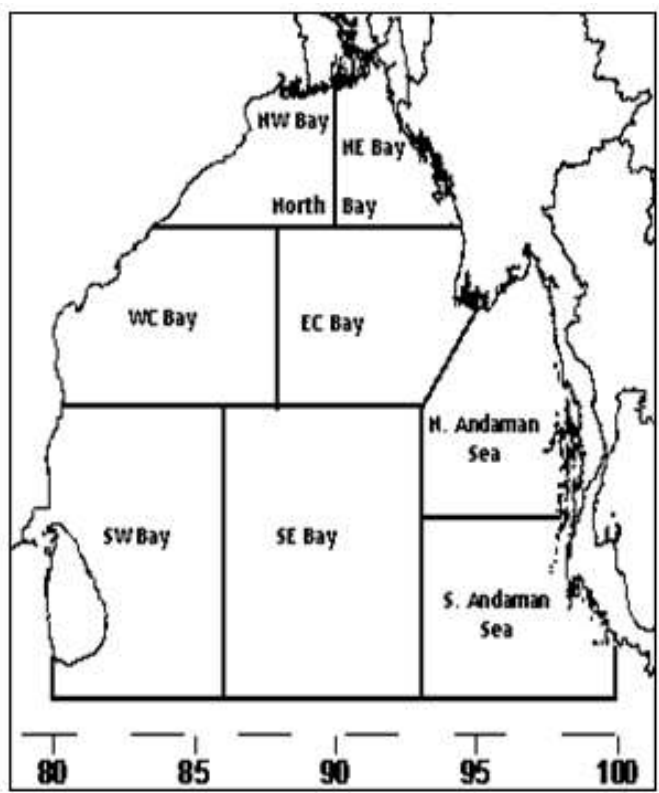

Fig. 1: Regions of the Bay of Bengal

Table -1: Classification of cyclonic disturbances in Bangladesh

\begin{tabular}{|l|l|l|l|}
\hline Sl. no. & Category of disturbances & Range of wind speed $(\mathrm{km} / \mathrm{h})$ & Bar depth $(\mathrm{hPa})$ \\
\hline 1 & Low & $<31$ & $\geq 1-1.5$ \\
\hline 2 & Well Marked Low & $31-40$ & $\geq 2-2.4$ \\
\hline 3 & Depression & $41-51$ & $\geq 2.5-3.7$ \\
\hline 4 & Deep Depression & $52-61$ & $\geq 4-4.5$ \\
\hline 5 & Cyclone & $62-88$ & $\geq 5.9-11.2$ \\
\hline 6 & Severe Cyclone & $89-117$ & $\geq 11.7-20.2$ \\
\hline 7 & Very Severe Cyclone & $118-219$ & $\geq 21.9$ \\
\hline 8 & Super Cyclone & $\geq 220$ & $\geq 22$ \\
\hline
\end{tabular}

\section{Mann-Kendall (MK) trend test}

The Mann-Kendall [Mann, 1945, Kendall, 1975] test (MK test) is a nonparametric trend test that involves the ranks for each element in the data series and is a statistical hypothesis testing procedure for the existence of trends; it does not estimate the slope of trends. The magnitude of the trends was estimated using Sen's slope [Sen, 1968]; according to Hirsch et al., 1982, Sen's method is robust against extreme outliers. The Mann-Kendall test was employed to detect presence of positive or negative trend in time series data while Sen's method was used to compute the magnitude of the change in rainfall.

One of the most used non-parametric tests to identify presence of trends in time series data is the Mann-Kendall test. Missing values in time series data are allowed in Mann-Kendall trend test and the data do not require conforming to any particular distribution [Yu et al, 1993]. The sign of difference is identified after all subsequent observed values are compared and the difference between the later-observed values and earlier-observed values are compared in the MannKendall test. Each-later observed value is analyzed with all earlier-observed values. If laterobserved values tend to be larger than earlier-observed values, an increasing trend can be identified while a decreasing trend can be recognized if later-observed values tend to be smaller than earlier-observed values. Linear regression method is used to estimate the slope of possible linear trend in time series but if there are gross data errors or outliers in time series, the estimated slope can be different from the true slope of linear trend.

Since Sen's slope estimator is not affected from gross data error or outliers, it is used to estimate the slope for Mann-Kendall test even with missing data. Possible slopes between all possible data pairs can be calculated by Sen's slope estimator. The initial value of the Mann-Kendall test statistic $S$ is set to 0 and it indicates there is no trend. It increases the $\mathrm{S}$ value by 1 when a later-observed value is higher than earlier-observed value and decreases by 1 when a later-observed value is lower than an earlier-observed value. The final value of $S$ is computed by the net results of those increases and decreases. Mann-Kendall method firstly calculates S statistic which indicates the sum of the difference between the 
data points indicated in following equation.

$$
S=\sum_{k=1}^{n-1} \sum_{j=k+1} \operatorname{sgn}\left(x_{i}-x_{k}\right)
$$

Where; $x_{j}$ is observed value at time $j, x_{k}$ is observed valu at time $k, j$ is time after time $k$ and $n$ is the length of the data set.

The sign of the value is defined as follows:

$$
\operatorname{Sgn}\left(x_{i}-x_{k}\right)=\left\{\begin{array}{cl}
1 & \text { if } x_{j}-x_{k}>0 \\
0 & \text { if } x_{j}-x_{k}=0 \\
-1 & \text { if } x_{j}-x_{k}<0
\end{array}\right.
$$

The statistical significant of $\mathrm{S}$ is checked using a test statistic (or $\mathrm{z}$ score):

$$
Z=\left\{\begin{array}{l}
\frac{s-1}{\sqrt{\operatorname{Var}(S)}} ; \mathrm{S}>0 \\
0 \\
\frac{S+1}{\sqrt{\operatorname{Var}(S)}} ; \mathrm{S}<0
\end{array}\right.
$$

The variance of $\mathrm{S}$ can be computed as:

$$
\mathbf{N}(\mathrm{N}-1)(2 \mathrm{~N}+5)-\sum_{J=1}^{q} \mathbf{t}_{\mathrm{p}}\left(\mathbf{t}_{\mathrm{p}}-\mathbf{1}\right)\left(\mathbf{t}_{\mathrm{p}}+5\right)
$$

$$
\operatorname{Var}(\mathbf{S})=
$$

\section{8}

Where; $\mathrm{N}$ indicates the number of data points, $\mathrm{q}$ indicates the number of tied groups (a tied group is a set of sample data having the same value) and $t$ indicates the number of data points in the $\mathrm{p}^{\text {th }}$ group. The MannKendall method test the null hypothesis, $\mathrm{H}_{0}$, is that data indicate no distinct trend against the alternative hypothesis $\mathrm{Hi}$ is that data indicate a trend. Two tailed test is used to decide whether or not the null hypothesis should be rejected in favor of hypothesis test. The null hypothesis, $\mathrm{H}_{0}$ is tested by the $\mathrm{Z}$ test statistic value. A decreasing trend is identified if $\mathrm{Z}$ is negative and an increasing trend is identified if the $\mathrm{Z}$ is positive. $\mathrm{H}_{0}$ is rejected at $0.1,0.05,0.01$ and 0.001 significance levels if the absolute value of $\mathrm{Z}$ is greater than $\mathrm{Z}_{1-\alpha / 2}$, where $\mathrm{Z}_{1-\alpha / 2}$ is taken from the standard normal cumulative distribution tables. The magnitude of the trend over time is estimated according to Sen, 1968. The median slope of all pair wise comparisons indicates the trend slope and the slopes of

Where

$$
Q_{i}=x_{j}-x_{k} / j-k
$$

$\mathbf{Q}_{\mathbf{i}} \quad$ : Slope between data points

$\mathbf{x}_{\mathbf{j}} \quad$ : Data measurement at time $\mathrm{j}$,

$\mathbf{x}_{\mathbf{k}} \quad$ : Data measurement at time $\mathrm{k} \quad$ and $\mathrm{j}>\mathrm{k}$.

If there are $\mathrm{n}$ values of $\mathrm{x}_{\mathrm{j}}$ in the time series Sen's slope estimator is the median of $\mathrm{N}(\mathrm{N}-1) / 2$ pairwise slopes. The Sen's estimator is:

$$
\begin{aligned}
& \mathbf{Q}=\mathbf{Q}_{(\mathrm{N}+1 / 2)} \text { if } \mathrm{N} \text { is odd, } \\
& \mathbf{Q}=1 / 2\left[\mathbf{Q}_{(\mathrm{N} / 2)}+\mathbf{Q}_{(\mathrm{N}+2) / 2}\right] \text { if } \mathrm{N} \text { is even }
\end{aligned}
$$

\section{Results and Discussion}

\subsection{Seasonal and annual trend of Depression over the Bay of Bengal}

In order to study the variability of seasonal frequency of depressions, the seasonal number of occurrence of depressions in monsoon and post-monsoon season for the 33years from 1981 - 2014 are shown in [fig. (2-3)] and discussed in this section. In monsoon season the value of $\mathrm{Z}$ is found -1.67 and the Mann- 


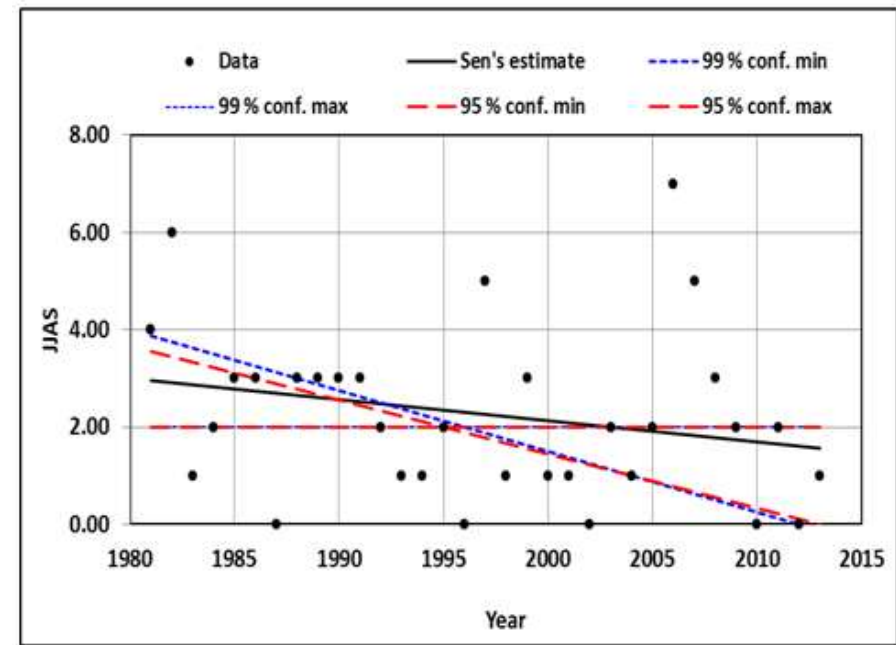

$\begin{array}{ll}\text { Name: Monsoon } \\ \text { Depression } \\ \text { Test S } \\ \text { Test Z } & -1.67 \\ \text { Signific. } & + \\ \text { Q } & -0.043 \\ \text { Qmin99 } & -0.125 \\ \text { Qmax99 } & 0.000 \\ \text { Qmin95 } & -0.111 \\ \text { Qmax95 } & 0.000 \\ \text { B } & 2.96 \\ \text { Bmin99 } & 3.88 \\ \text { Bmax99 } & 2.00 \\ \text { Bmin95 } & 3.56 \\ \text { Bmax95 } & 2.00\end{array}$

Fig-2: Time series and trend statistics of frequency of depression in Monsoon during 1981-2013

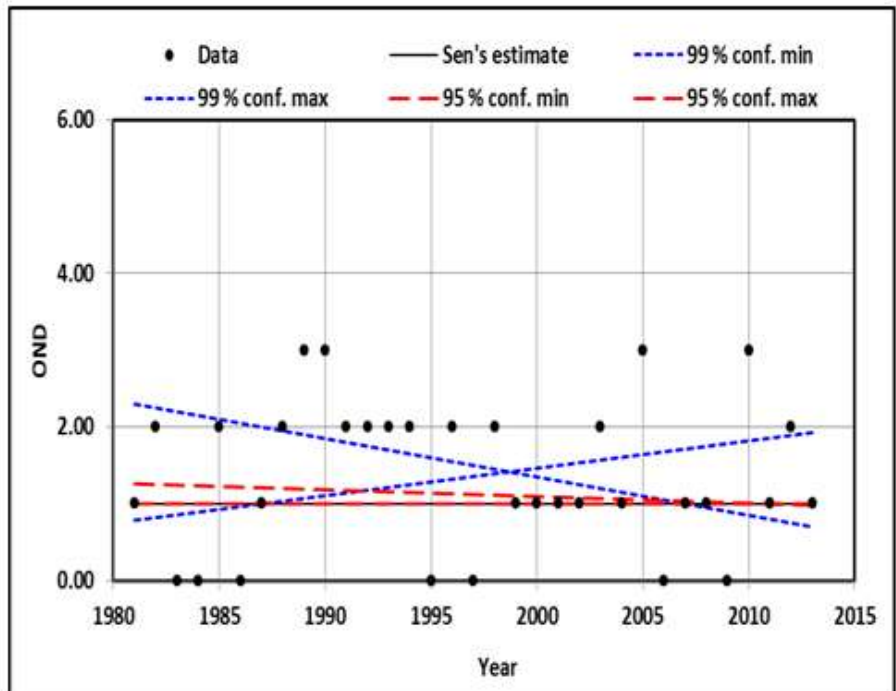

$\begin{array}{ll}\text { Name : post-monsoon } \\ \text { Depression } \\ \text { Test S } \\ \text { Test Z } & \\ \text { Signific. } & -0.23 \\ \text { Q } & 0 \\ \text { Qmin99 } & -0.050 \\ \text { Qmax99 } & 0.036 \\ \text { Qmin95 } & -0.009 \\ \text { Qmax95 } & 0.000 \\ \text { B } & 1 \\ \text { Bmin99 } & 2.30 \\ \text { Bmax99 } & 0.79 \\ \text { Bmin95 } & 1.26 \\ \text { Bmax95 } & 1.00\end{array}$

Fig-3: Time series and trend statistics of frequency of depression in Post-Monsoon during 1981-2013

Kendall test indicates a decreasing trend, it is appropriate at $90 \%$ statistical confidence level. In the post-monsoon season the value of $\mathrm{Z}$ is found -0.23 which is not statistically significant. The annual frequency of depressions are shown in the Fig. no. [4] and the value of $\mathrm{Z}$ is -1.18 which is also statistically insignificant The significance level of the Mann-Kendall test for the monsoon, pre-monsoon and annual is given in the Table 2.

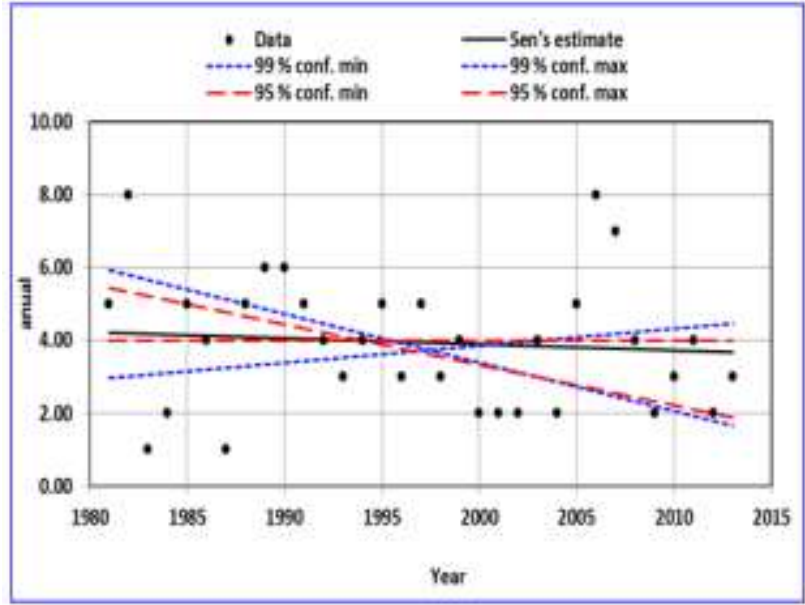

\begin{tabular}{|c|c|}
\hline \multirow{2}{*}{\multicolumn{2}{|c|}{$\begin{array}{l}\text { Name: Annual } \\
\text { Depression }\end{array}$}} \\
\hline & \\
\hline $\begin{array}{l}\text { Test Z } \\
\text { Signific. }\end{array}$ & -1.18 \\
\hline$Q$ & -0.017 \\
\hline Qmin 99 & -0.133 \\
\hline Qmax99 & 0.047 \\
\hline Qmin95 & $-0,111$ \\
\hline Qmax95 & 0.000 \\
\hline B & 4.22 \\
\hline Bming9 & 5.93 \\
\hline$B \max 99$ & 2.97 \\
\hline$B \min 95$ & 5.44 \\
\hline$B \max 95$ & 4.00 \\
\hline
\end{tabular}

Fig-4: Time series and trend statistics of frequency of annual depression during 1981-2013 
Table 2: Depression trends of Bangladesh over the 33-years period by using Mann-Kendall test

\begin{tabular}{|l|l|l|}
\hline Seasonal/Annual & Trend of depression & Significant level \\
\hline Monsoon & -1.67 & + \\
\hline Post-monsoon & -0.23 & - \\
\hline Annual & -1.18 & - \\
\hline
\end{tabular}

- $\quad$ Not significant. +Significance level $<=90 \%$.

\subsection{Seasonal and annual trend of cyclonic storm over the Bay of Bengal}

The variability of post-monsoon and annual frequency of cyclonic storms, for the 33years from 1981 2014 are depicted in [fig. (5-6)]. The significance level of the Mann-Kendall test for the post-monsoon, and annual is given in the Table 3. In post-monsoon season the value of $\mathrm{Z}$ is found -0.34 and the Mann- Kendall test indicates a decreasing trend, but it is statistically insignificant. The annual frequency of cyclonic storms are shown in the Fig. no. [6], and the value of $\mathrm{Z}$ is -0.23 which is also statistically insignificant.

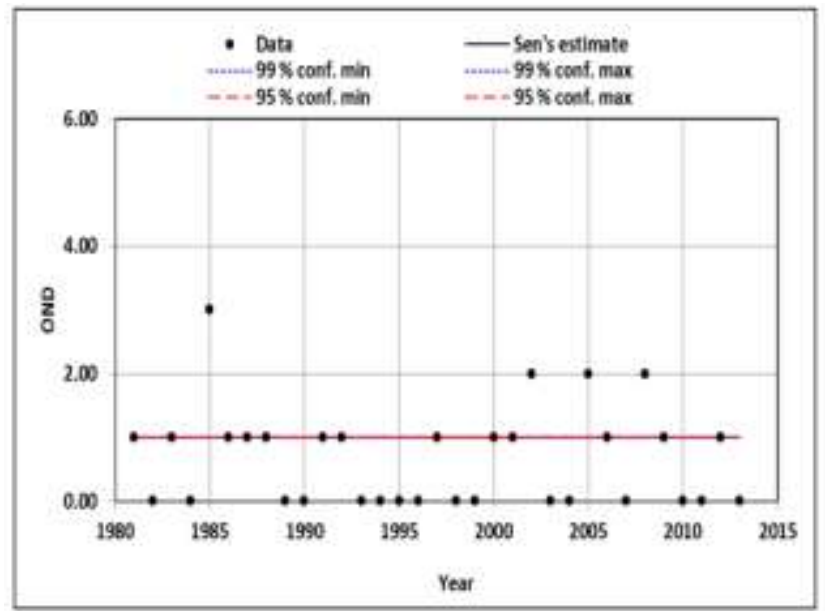

\begin{tabular}{|lc|}
\hline Name & Cycionic Storm \\
Test S & \\
Test Z & -0.34 \\
Signific. & \\
Q & 0.000 \\
Qmin99 & 0.000 \\
Qmax99 & 0.000 \\
Qmin95 & 0.000 \\
Qmax95 & 0.000 \\
B & 1.000 \\
Bmin99 & 1.000 \\
Bmax99 & 1.000 \\
Bmin95 & 1.000 \\
Bmax95 & 1.000 \\
& \\
& \\
\hline
\end{tabular}

Fig-5: Time series and trend statistics of frequency of post-monsoon cyclonic storm during 1981-2013

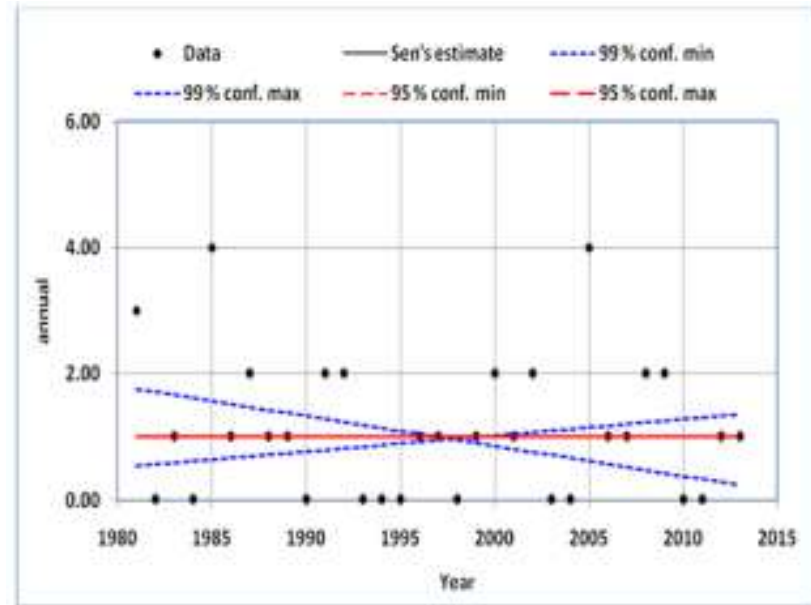

\begin{tabular}{ll} 
Name Cyclonic Storm \\
Test S \\
Test Z & -0.23 \\
Signific. & \\
Q & 0.000 \\
Qmin99 & -0.048 \\
Qmax99 & 0.026 \\
Qmin95 & 0.000 \\
Qmax95 & 1.000 \\
B & 1.76 \\
Bmin99 & 1.76 \\
Bmax99 & 0.54 \\
Bmin95 & 1.000 \\
Bmax95 & 1.000 \\
& \\
& \\
\hline
\end{tabular}

Fig-6: Time series and trend statistics of frequency of annual cyclonic storm during 1981-2013

Table 3: cyclone trends of Bangladesh over the 33-years period by using Mann-Kendall test

\begin{tabular}{|l|l|l|}
\hline Seasonal/annual & Trend of depression & Significant level \\
\hline Post-monsoon & -0.34 & - \\
\hline Annual & -0.23 & - \\
\hline
\end{tabular}

- Not significant.

\subsection{Seasonal and annual trend of severe cyclonic storm over the Bay of Bengal}

The variability of pre-monsoon, post-monsoon and annual frequency of severe cyclonic storms, for the 33years from 1981-2014 are depicted in [fig. (7-9)].The significance level of the Mann-Kendall test for the premonsoon, post-monsoon and annual is given in the Table 4. In post-monsoon season and the annual value of $\mathrm{Z}$ is 
found -2.20 and -2.21 respectively \& the Mann- Kendall test indicates a decreasing trend, which is statistically significant in $95 \%$ confidence level. No trend is found in pre-monsoon season.

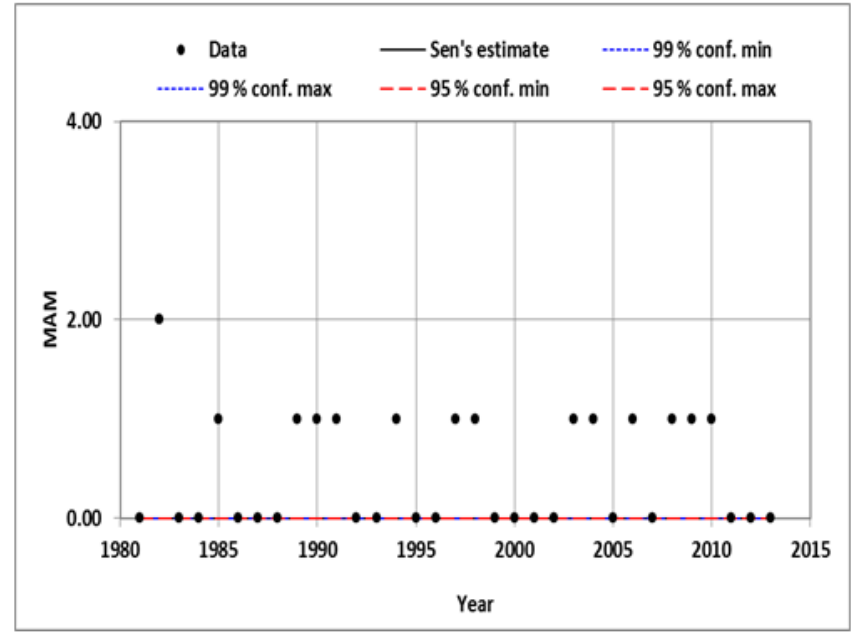

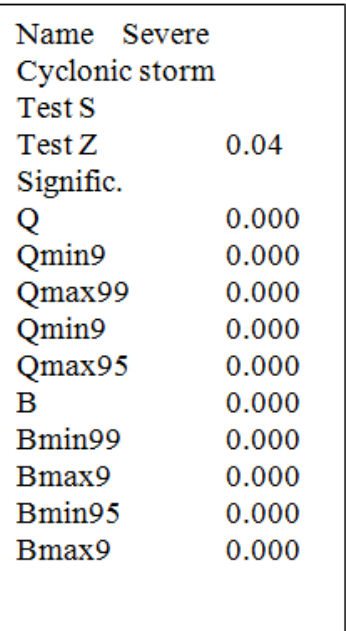

Fig-7: Time series and trend statistics of frequency of pre-monsoon severe cyclonic storm during 1981-2013

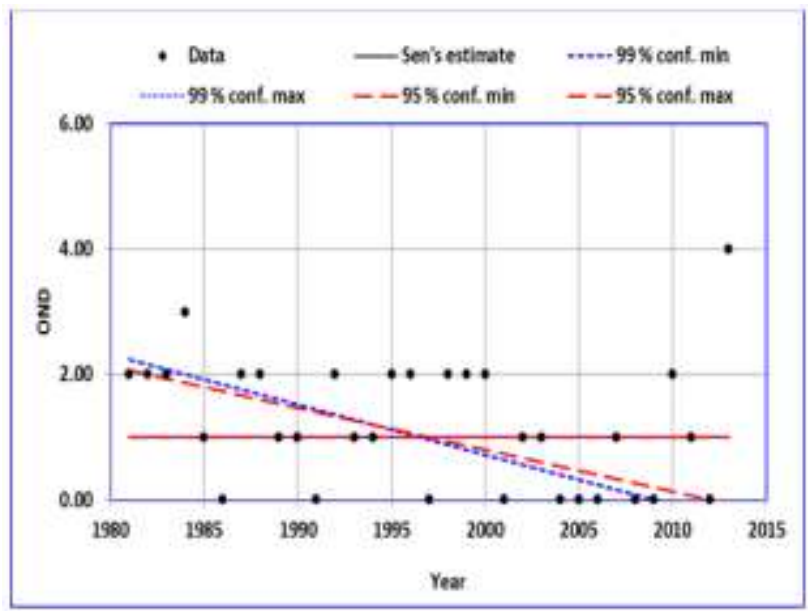

\begin{tabular}{|c|c|}
\hline \multicolumn{2}{|c|}{$\begin{array}{l}\text { Name Severe } \\
\text { Cyclonic storm }\end{array}$} \\
\hline Test Z & -2.20 \\
\hline Signific. & + \\
\hline Q & 0.000 \\
\hline Qmin99 & -0.080 \\
\hline Qmax99 & 0.000 \\
\hline Qmin95 & -0.067 \\
\hline Qmax95 & 0.000 \\
\hline B & 1.00 \\
\hline$B \min 99$ & 2.24 \\
\hline$B \max 99$ & 1.00 \\
\hline Bmin95 & 2.07 \\
\hline$B \max 95$ & 1.00 \\
\hline
\end{tabular}

Fig-8: Time series and trend statistics of frequency of post-monsoon severe cyclonic storm during 1981 2013

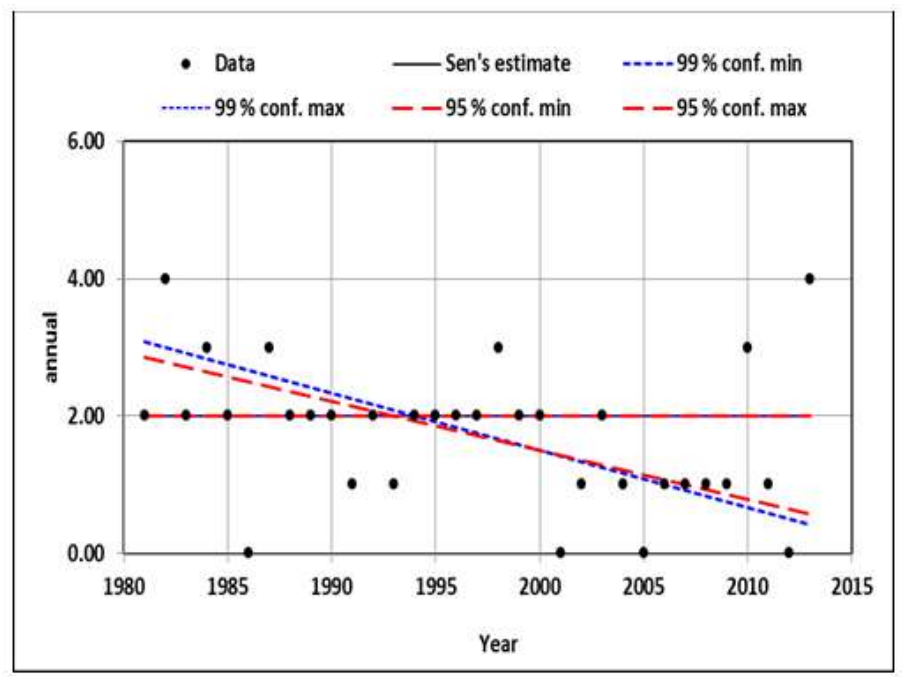

\begin{tabular}{|c|c|}
\hline Name $\mathrm{S}$ & \\
\hline Cyclonic & \\
\hline Test $\mathrm{S}$ & \\
\hline Test $Z$ & -2.21 \\
\hline Signific. & $*$ \\
\hline Q & 0.000 \\
\hline Qmin99 & -0.083 \\
\hline Qmax99 & 0.000 \\
\hline Qmin95 & -0.071 \\
\hline Qmax95 & 0.000 \\
\hline B & 2.00 \\
\hline Bmin 99 & 3.08 \\
\hline Bmax99 & 2.00 \\
\hline $\mathrm{Bmin} 95$ & 2.86 \\
\hline Bmax95 & 2.00 \\
\hline
\end{tabular}

Fig-9: Time series and trend statistics of frequency of annual severe cyclonic storm during 1981-2013 
Table 4: Severe Cyclone trends of Bangladesh over the 33-years period by using Mann-Kendall test

\begin{tabular}{|l|l|l|}
\hline Seasonal/Annual & Trend of depression & Significant level \\
\hline Pre-Monsoon & 0.04 & - \\
\hline Post-monsoon & -2.20 & $*$ \\
\hline Annual & -2.21 & $*$ \\
\hline
\end{tabular}

- Not significant, $*$ Significance level $<=95 \%$.

\subsection{Seasonal and annual trend of ( D + CS + SCS ) over the Bay of Bengal}

4.The variability of pre-monsoon, monsoon, post-monsoon and annual frequency of cyclonic storms (D+CS+SCS), for the 33years from 198-2014 are shown in [fig. (10-13)].The significance level of the MannKendall test for the pre-monsoon, monsoon, post-monsoon and annual is given in the Table 5. In monsoon season the value of $\mathrm{Z}$ is found -1.99 and the Mann- Kendall test indicates a decreasing trend, it is statistically significant. The annual frequency of cyclonic storms are shown in the Fig. no. [13], and the value of $\mathrm{Z}$ is -1.47 which is statistically insignificant.

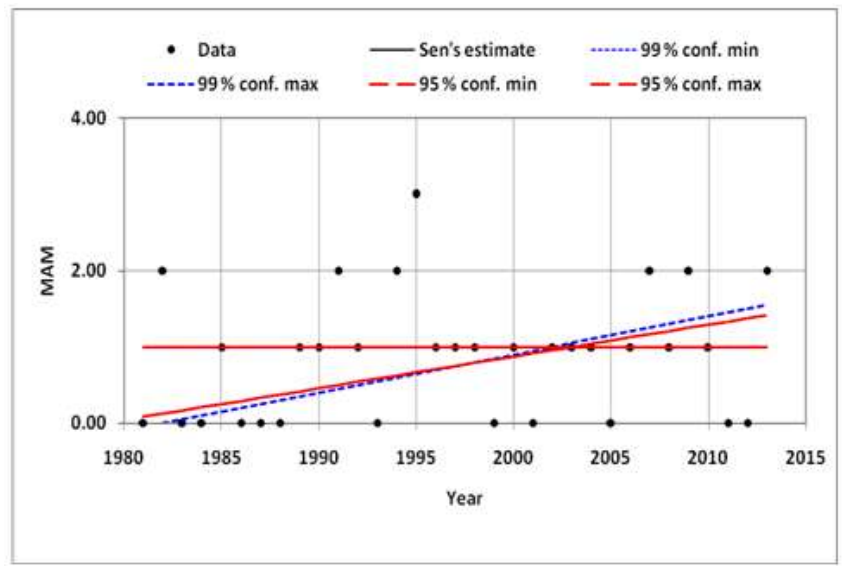

\begin{tabular}{|ll|}
\hline $\begin{array}{l}\text { Name } \\
\text { Test S }\end{array}$ & D+CS+SCS \\
Test $Z$ & \\
Signific. & 1.15 \\
Q & 0.000 \\
Qmin9 & 0.000 \\
Qmax99 & 0.050 \\
Qmin9 & 0.000 \\
Qmax95 & 0.042 \\
B & 1.00 \\
Bmin99 & 1.00 \\
Bmax9 & -0.05 \\
Bmin95 & 1.000 \\
Bmax9 & 0.08 \\
\hline
\end{tabular}

Fig-10: Time series and trend statistics of frequency of pre-monsoon (D + Cs + SCS ) during 1981-2013

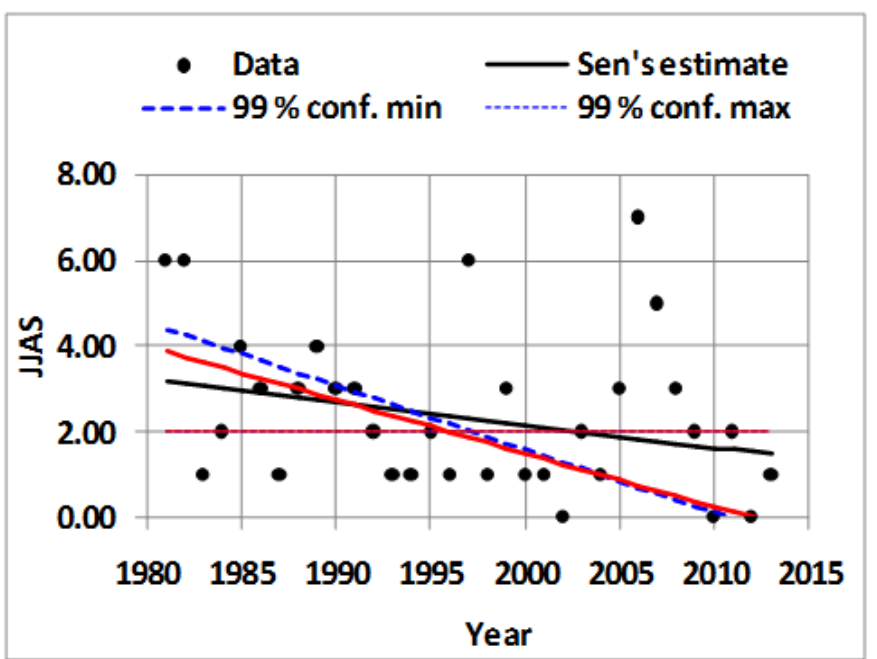

\begin{tabular}{|lc|}
\hline Name & D+CS+SCS \\
Test S & \\
Test Z & -1.99 \\
Signific. & $*$ \\
Q & 0.053 \\
Qmin9 & -0.148 \\
Qmax99 & 0.000 \\
Qmin95 & -0.125 \\
Qmax95 & 0.000 \\
B & 3.16 \\
Bmin99 & 4.41 \\
Bmax99 & 2.00 \\
Bmin95 & 3.88 \\
Bmax95 & 2.00 \\
& \\
& \\
\hline
\end{tabular}

Fig-11: Time series and trend statistics of frequency of monsoon D + Cs + SCS during 1981-2013 


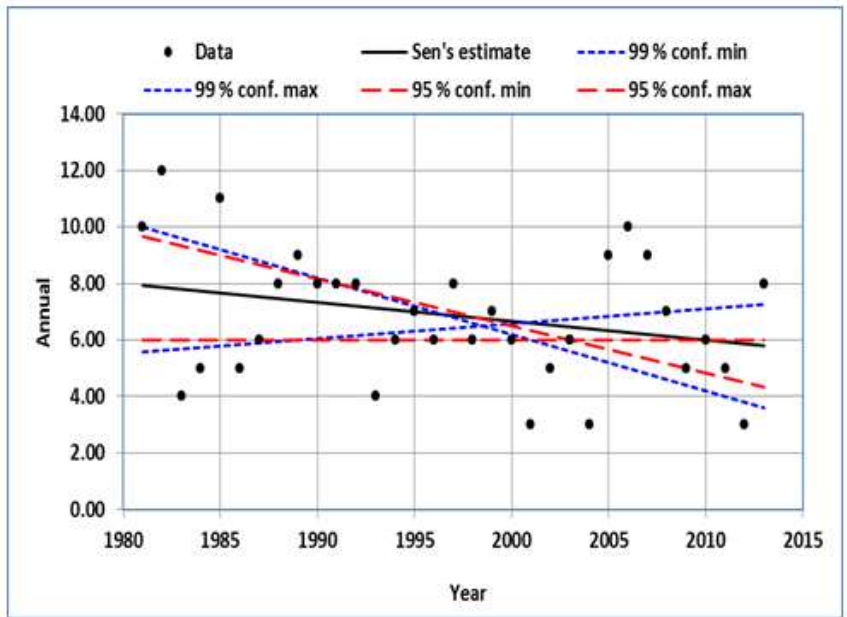

$\begin{array}{|lc|}\text { Name } & \text { D+CS+SCS } \\ \text { Test S } & \\ \text { Test Z } & -1.47 \\ \text { Signific. } & \\ \text { Q } & -0.67 \\ \text { Qmin99 } & -2.00 \\ \text { Qmax99 } & 0.053 \\ \text { Qmin95 } & -0.167 \\ \text { Qmax95 } & 0.000 \\ \text { B } & 7.93 \\ \text { Bmin99 } & 10.00 \\ \text { Bmax99 } & 5.58 \\ \text { Bmin95 } & 9.67 \\ \text { Bmax95 } & 6.00 \\ & \end{array}$

Fig-12: Time series and trend statistics of frequency of post-monsoon ( D + CS + SCS) during 1981-2013

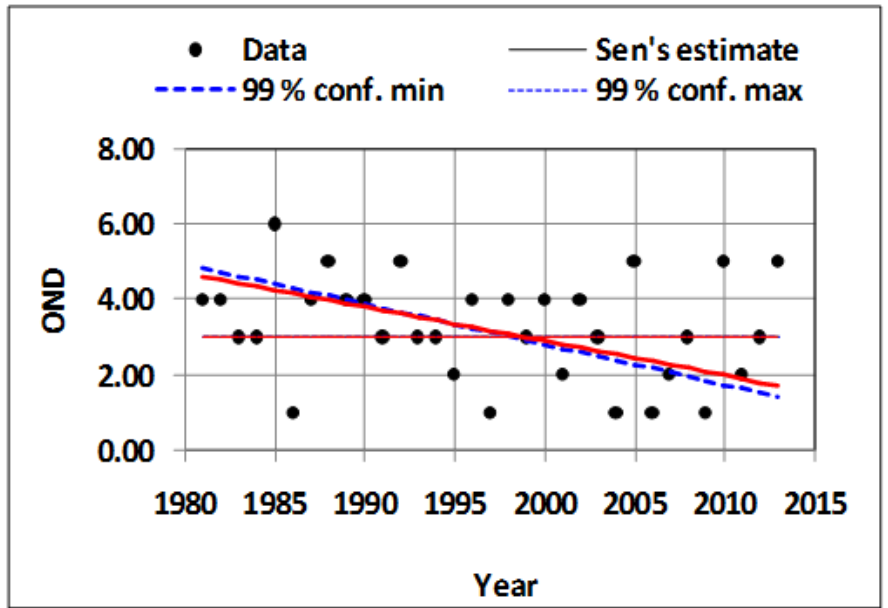

$\begin{array}{ll}\text { Name } & \text { D+CS+SCS } \\ \text { Test S } & \\ \text { Test } Z & -1.32 \\ \text { Signific. } & \\ \text { Q } & 0.000 \\ \text { Qmin99 } & -0.107 \\ \text { Qmax99 } & 0.000 \\ \text { Qmin95 } & -0.091 \\ \text { Qmax95 } & 0.000 \\ \text { B } & 3.00 \\ \text { Bmin99 } & 4.85 \\ \text { Bmax99 } & 3.00 \\ \text { Bmin95 } & 4.64 \\ \text { Bmax95 } & 3.00 \\ & \end{array}$

Fig-13: Time series and trend statistics of annual frequency of D+Cs+SCS during 1985-2013

Table 5: Seasonal and annual trend of (D + CS + SCS ) over the Bay of Bengal During 33-years Period by using Mann-Kendall test

\begin{tabular}{|l|l|l|}
\hline Seasonal/annual & Trend of rainfall & Significant level \\
\hline Pre-monsoon & 1.15 & - \\
\hline Monsoon & -1.99 & $*$ \\
\hline Post-monsoon & -1.32 & - \\
\hline Annual & -1.47 & - \\
\hline
\end{tabular}

IV. Conclusions

The present study analyses the trend of cyclonic storms over Bangladesh for a 33-years period between 1981 and 2014 by using Mann-Kendall test and Sen's method. The results presented in this paper reveal negative trends over Bangladesth during 33-years period. These results indicate, Bangladesh has experienced a lower trend of tropical disturbances.

\section{Acknowledgement}

The authors are thankful to Bangladesh Meteorological Department (BMD) for providing data and support. We are also grateful to Mr. Md. Shadekul Alam for his cordial co-operation and constructive suggestions. Thanks are due to Mr. Shamsuddin Ahamed, Director, Bangladesh Meteorological Department for his suggestion and constant encouragement. Authors are also thankful to Finish Meteorological Institute for providing Mann-Kendall Excel template. 


\section{References}

[1]. Camargo S J, Emanuel KA and Sobel AH, 2007: Use of a genesis potential index to diagnose ENSO effects on tropical cyclone genesis J. Clim. 20 4819-34

[2]. Camargo S J, Wheeler M C and Sobel A H, 2009: Diagnosis of the MJOmodulation of tropical cyclogenesis using an empirical index J. Atmos. Sci. 66 3061-74

[3]. Chan, J. C. - L., 1985: Tropical cyclone activity in the northwest Pacific in relation to the El-Nino/Southern Oscillation phenomenon, Mon. Wea. Rev, 113, 599-606.

[4]. Ding Y and Sikka D R, 2006: Synoptic Systems and Weather The Asian Monsoon (Berlin: Springer) pp 131-201.

[5]. Emanuel K A and Nolan D S, 2004: Tropical cyclone activity and global climate Preprints 26th Conf. on Hurricanes and Tropical Meteorology (Miami, FL:Am.Meteorol. Soc.) pp 240-1

[6]. Girish kumar MS, Suprit K, Vishnu S, Thanga Prakash V P and Ravichandran M, 2014: The role of ENSO and MJO on rapid intensification of tropical cyclones in the Bay of Bengal during October-December Theo. Appl. Climatol. 120, 797-810

[7]. Gray W M, 1968: Global view of the origin of tropical disturbances and storms, Mon. Weather Rev. 96, 669-700

[8]. Gray W M, 1979: Hurricanes: their formation, structure and likely role in the tropical circulation Meteorology Over the Tropical Oceans ,77, 155-218

[9]. Gray, W. M., 1984: Atlantic seasonal hurricane frequency. Part I: El-Nino and 30 mb quasi-biennial oscillation influences. Mon. Wea. Rev., 112, 1649-1668.

[10]. Hirsch, R.M., Slack, J.R. and Smith, R.A., 1982: Techniques of trend analysis for monthly water quality data, Water Resources Research, 18 (1), 107-121.

[11]. Jadhav S K and Munot A A, 2009: Warming SST over Bay of Bengal and decrease in formation of cyclonic disturbances over the Indian region during southwest monsoon season, Theo. Appl. Climatol. 96, 327-36

[12]. Kendall, M.G., 1975: Rank correlation methods. London: Charles Griffin.

[13]. Kumar J R and Dash S K, 2001: Interdecadal variations of characteristics of monsoon disturbances and their epochal relationships with rainfall and other tropical features Int. J. Climatol. 21 759-71

[14]. Li Z, Yu W, Li T, Murty V S N and Tangang F, 2013: Bimodal character of cyclone climatology in Bay of Bengal modulated by monsoon seasonal cycle J. Clim. $261033-46$

[15]. Mann, H.B., 1945: Non-parametric test against trend, Econometrica, 13, 245-259.

[16]. Mandke S K and Bhide U V, 2003: A study of decreasing storm frequency over Bay of Bengal, J. Ind. Geophys. Uni. 7 53-8

[17]. Nicholls, N., 1984: Predictability of interannual variations of Australian seasonal tropical cyclone activity. Mon. Wea, Rev., 113, $1144-1149$

[18]. Patwardhan S Kand Bhalme H N ,2001: A study of cyclonic disturbances over India and the adjacent ocean, Int. J. Climatol. 21, 527-34

[19]. Prajeesh A G, Ashok K and Rao D V B, 2013: Falling monsoon depression frequency: a Gray-Sikka condition perspective Scientific Report 3, 1-8

[20]. Rajeevan M, De U S and Prasad R K, 2000: Decadal variation of sea surface temperatures, cloudiness and monsoon depressions in the north Indian Ocean, Curr. Sci. 79, 283-5

[21]. Rao B R S, Rao D V B and Rao V B, 2004: Decreasing trend in the strength of tropical easterly jet during the Asian summer Environ. Res. Lett. 11 (2016) 014011.monsoon season and the number of tropical cyclonic systems over Bay of Bengal Geophys. Res. Lett. 31, L14103

[22]. Rao V B, Ferreira C C, Franchito S H and Ramakrishna S S V S, 2008: In a changing climate weakening tropical easterly jet induces more violent tropical storms over the north Indian Ocean, Geophys. Res. Lett. 35 L15710

[23]. Roxy M K, Ritika K, Terray P, Murtugudde R, Ashok K and Goswami B N, 2015: Drying of Indian subcontinent by rapid Indian Ocean warming and a weakening land-sea thermal gradient Nat. Commun. 67423

[24]. Sen, P.K., 1968: Estimates of regression coefficients based on Kendall's tau. Journal of the American Statistical Association, 63, 1379-1389.

[25]. Shapiro, L. 1982: Hurricane climate fluctuations, Part II, Relation to large scale circulation. Mon. Wea, Rev., 110,1014 -1023.

[26]. Sikka D R and Gadgil S 1980: Onthe maximum cloud zone and the ITCZ over Indian, longitudes during the southwest monsoon Mon. Weather Rev. 108.11 1840-53

[27]. Sikka D R, 1977: Some aspects of the life history, structure andmov ement of monsoon depressions, Pure Appl. Geophys. $115,1501-29$

[28]. Sikka D. R., 1980: Some aspects of the large scale fluctuations of summer monsoon rainfall over India in relation to fluctuations in the planetary and regional scale circulation parameters Proc. Indian Acad. Sci. Earth Planet. Sci. 89 179-95

[29]. Singh, O. P. and R. K. Rout, 1999: Frequency of cyclonic disturbances over the North Indian Ocean during ENSO years. Proceeding of TROPMET-99, Chennai (To appear).

[30]. Sivakumar MVK, Das HP and Bruninio, 2005: Impacts of present and future climate variability and change on agriculture and forestry in the arid and semi-arid tropics, Clim. Change 70, 31-72

[31]. Yanase W, Satoh M, Taniguchi H and Fujinami H, 2012: Seasonal and intra seasonal modulation of tropical cyclogenesis environment over the Bay of Bengal during the extended summer monsoon J. Clim. 25 2914-30

[32]. Yu, Y.S., S. Zou and D. Whittemore, 1993: Nonparametric trend analysis of water quality data of rivers in Kansas, J. Hydrol., 150: 61-80. 